\title{
Morphological and Thermal Properties of Composites Prepared with Poly(lactic acid), Poly(ethylene-alt-maleic anhydride), and Biochar from Microwave-pyrolyzed Jatropha Seeds
}

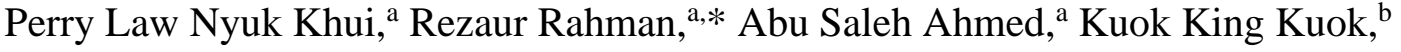 \\ Muhammad Khusairy Bin Bakri, ${ }^{a}$ Diana Tazeddinova, ${ }^{\mathrm{c}}$ Zhumayeva Araigul \\ Kazhmukanbetkyzy, ${ }^{\mathrm{d}}$ and Baibatyrov Torebek ${ }^{\mathrm{d}}$
}

\begin{abstract}
The morphological and thermal properties of composites containing a bioplastic blend and micro/nano-sized biochar from pyrolyzed jatropha seeds from microwave pyrolyzed jatropha seeds were investigated using scanning electron microscopy, Fourier transform infrared spectroscopy, thermogravimetric analysis, and differential scanning calorimetry. The biocomposite samples exhibited a brittle structure with a slightly ductile chip-like appearance. The Fourier transform infrared spectroscopy results for the PLA/PEMA/BC bio-composites were comparable to the PLA/BC biocomposites. A lower bio-filler content had more pronounced peak intensities than the higher bio-filler content biocomposites. The added PEMA compatibilizer in the PLA/PEMA/BC biocomposite showed more pronounced peaks, which indicated slightly improved bonding/interaction between the bio-filler and the matrix. Overall, increasing bio-filler content did not drastically affect the functional groups of the biocomposites. Thermogravimetric and differential scanning calorimetry analysis showed the developed biocomposites had a slight improvement in thermal stability, in comparison to the PLA sample. Improvements in the thermal stability of the PLA/PEMA/BC biocomposite could be attributed to the additional hydroxyl group, which was due to the added PEMA in the PLA and PLA/BC. According to the results of the analysis of the developed biocomposites, the biocomposites were more brittle and had reasonable thermal stability.
\end{abstract}

Keywords: Format; Biochar; Bio-composites; Characterization; Carbon; Jatropha

Contact information: a: Faculty of Engineering, Universiti Malaysia Sarawak, Jalan Datuk Mohammad Musa, Kota Samarahan, Sarawak 94300 Malaysia; b: Faculty of Engineering, Computing and Science, Swinburne University of Technology Sarawak Campus, Jalan Simpang Tiga, Kuching, Sarawak 93350 Malaysia; c: Faculty of Engineering, South Ural State University, 76, Lenin Prospekt, Chelyabinsk 454080 Russia; d: Zhangir Khan West Kazakhstan Agrarian - Technical University, Zhangir Khan St 51, Uralsk 090009 Kazakhstan; *Corresponding author: rmrezaur@unimas.my

\section{INTRODUCTION}

There has been only limited research regarding biochar specifically derived via the microwave pyrolysis of jatropha seeds (Figueiredo et al. 2011; Franceschi et al. 2015; Das et al. 2018). The fruits and seeds from Jatropha curcas L. are known to be a good alternative source for ecological biodiesel. There are numerous studies showing good oil yield from jatropha seeds and their potential applicability as a biodiesel using pyrolysis processing procedures as the extraction method (Carels 2009; Figueiredo et al. 2011; 
Kanaujia et al. 2016; Sugumaran et al. 2017; Ruggiero et al. 2019). After pressing a high portion of oil from the fruits and seeds, the residual material is considered toxic and requires additional chemical processing to be used as agricultural feedstock (Ruggiero et al. 2019).

Previous research has been conducted on the synthesis and characterization of microwave pyrolysis jatropha seed biochar into micro/nano size bio-filler, which was successfully produced via ball milling processes (Khui et al. 2020). The continuation of the research is shown in this paper, involving the morphology and thermal properties of biocomposites synthesized from the produced bio-filler in a polylactic acid (PLA) biodegradable polymer matrix. The production of biocomposites could be further developed as well as made to meet specific demands by optimizing the biochar filler content and selecting the suitable processing method. According to literature, biochar in general is found to be an appropriate replacement for conventional fillers, e.g., carbon black, talc, and calcium carbonate $\left(\mathrm{CaCO}_{3}\right)$. Hence, expanding the applicability of biochar and its biocomposite derivatives to various applications, e.g., building, packaging, automotive, and electronics devices, is desirable (Das et al. 2018; Arrigo et al. 2020). In addition, low-cost bio-fillers are synthesized from various waste sources, which provides an added benefit to the circular economy solution (Arrigo et al. 2020).

Poulose et al. (2018) investigated the electrical, mechanical, thermal, and rheological properties of polypropylene reinforced composites using biochar derived from date-palm as a filler. The experimental results showed that the developed biocomposite had increased surface resistivity, stiffness, and a reduction in crystallinity with the addition of biochar. The researchers recommended modifying the biochar properties, e.g., surface area, porosity, surface functionalization (physical and/or chemical), as well as increasing the purity via the removal of ash content (Poulose et al. 2018).

PLA biodegradable composites reinforced with cellulose microcrystalline, fibers and nano-whiskers, carbon, wood fibers and flour have shown good performance in their mechanical and chemical properties (Mathew et al. 2005; Bogren et al. 2006; Petersson et al. 2007). Braun et al. (2006) described the methods for the composites with PLA reactive compatibilization with cellulose fibers. Flax, kenaf, bamboo, and hemp are the most used and utilized fibers to reinforce PLA to create biocomposites (Lee and Wang 2006; Masirek et al. 2007; Oksman et al. 2003; Pan et al. 2007; Zini et al. 2004). Micro-powders of the PLA were also filled with materials derived from agricultural by-products (Lezak et al. 2008; Mohamed et al. 2007; Nyambo et al. 2010). As compared to neat PLA, the composite modulus was improved, along with decreased elongation at break. Graupner et al. (2009) stated that the natural and man-made cellulose fibers show a positive influence on the PLAbased composites mechanical properties, whereas the fibers were oriented by a roller card.

Upon the review of numerous publications, there has been a lack of studies focusing on the development of biocomposite using carbon fillers from any pyrolysis product. Most researchers only focus on the study of biomass pyrolysis oil or biochar, as well as the type of pyrolysis process. The goal of this study, thus addressing the research gap, is to characterize the morphology and thermal properties of biocomposites using jatropha seed biochar as a bio-filler. In this study, Fourier-transform infrared spectroscopy (FTIR) and SEM were used to evaluate the functional and morphological properties of the manufactured composites, i.e. PLA, PLA/BC, PLA/PEMA, and PLA/PEMA/BC. The thermal stability and melting behavior under a constant rate of heating are also reported in this study. 


\section{EXPERIMENTAL}

\section{Materials}

The bio-filler used for the fabrication of the biocomposites was synthesized according to a previous study by Khui et al. (2020). The Jatropha seeds were pyrolyzed at $180{ }^{\circ} \mathrm{C}$ with a nitrogen flow of $0.5 \mathrm{~L} / \mathrm{min}$. The Jatropha biochar obtained were ground and ball mill to obtained it micro/nano sized, which will be used as bio-filler in the composites. to obtained The polylactic acid (PLA) and poly (ethylene-alt-maleic anhydride) were supplied by Sigma Aldrich (St. Louis, MO).

\section{Methods}

Biocomposite fabrication

The biocomposite processing temperature was set at $180{ }^{\circ} \mathrm{C}$ for the hot hydraulic molding press and $10{ }^{\circ} \mathrm{C}$ for the cold hydraulic molding press. The high temperature was due to the composition of the materials used, which resist thermal degradation and maintain sufficient strength and stiffness at the required operating temperature. The total processing time, from a dry mixture to a biocomposite, took $20 \mathrm{~min}$ to $25 \mathrm{~min}$ to complete. The following list defines the biocomposite and neat material sample abbreviations used for fabricating and testing shown in Table 1.

Table 1. Biocomposite Fabrication Samples

\begin{tabular}{|c|c|}
\hline Samples & $\begin{array}{c}\text { Material Ratios Generated Via A D-Optimal } \\
\text { Design Mixture }\end{array}$ \\
\hline Polylactic acid (PLA) & - \\
\hline $\begin{array}{c}\text { Polylactic acid + Poly (ethylene-alt-maleic } \\
\text { anhydride) (PLA/PEMA) }\end{array}$ & $\begin{array}{c}\text { PEMA weight percentage stayed constant at } \\
1 \mathrm{wt} \%\end{array}$ \\
\hline Polylactic acid + Bio-filler (PLA/BC) & $\begin{array}{c}\text { PLA/BC has a BC weight percentage of } 0.5 \\
\text { wt } \%, 1.25 \mathrm{wt} \%, 1.625 \mathrm{wt} \% \text {, and } 2.0 \mathrm{wt} \%\end{array}$ \\
\hline $\begin{array}{c}\text { Polylactic acid + Poly (ethylene-alt-maleic } \\
\text { anhydride) + Bio-filler (PLA/PEMA/BC) }\end{array}$ & $\begin{array}{c}\text { PLA/PEMA/BC has a BC weight percentage } \\
0.5 \mathrm{wt} \%, 1.25 \mathrm{wt} \%, 1.625 \mathrm{wt} \% \text {, and } 2.0 \mathrm{wt} \%\end{array}$ \\
\hline
\end{tabular}

Scanning electron microscopy (SEM) of the biocomposites

A Hitachi TM4000Plus tabletop microscope (Hitachi, Ltd., Tokyo, Japan) was used for the scanning electron microscopy analysis. The scanning electron microscopy for the samples was conducted according to ASTM standard E2015-04 (2014), which outlines the electron microscopy testing procedure. Magnifications up to 500x were utilized to observe the morphology of the biocomposite samples after fracturing due to the tensile test.

\section{Fourier transform infrared spectroscopy (FTIR) of the biocomposites}

A Fourier-transform infrared spectrophotometer (IRAffinity-1, Shimadzu Corporation, Kyoto, Japan) was used for the Fourier transform infrared spectroscopy (FTIR) analysis. The Fourier-transform infrared spectroscopy was conducted according to ASTM standard E168-16 (2016) and ASTM standard E1252-98 (2013) for qualitative and quantitative analysis, respectively. The spectrum scanning was conducted within a wavenumber range of 4000 to $400 \mathrm{~cm}^{-1}$ for each sample. Around $0.5 \mathrm{mg}$ sample was mixed with approximately $100 \mathrm{mg}$ dry potassium bromide $(\mathrm{KBr})$ powder, in a small agate pestle and press were employed to create a sample pellet for FTIR spectroscopy. Then, the mixture sample pellet was then taken into the sample holder inside the spectrometer. Fourier-transform infrared spectroscopy utilizes the infrared spectrum transmittance and 
absorption of the samples to develop a unique molecular fingerprint spectrum. The test was repeated numerous times by the IR Solution software, and the most representative results were selected by the software.

Thermogravimetric analysis (TGA) of the biocomposites

Thermogravimetric analysis (TGA), with a TGA Mettler Toledo analytical instrument, was used to determine the thermal stability and percentage weight loss of the biocomposites, either as a function of time or temperature under a constant rate of heating. The conditions for testing were as follows: a temperature of range of 40 to $500{ }^{\circ} \mathrm{C}$ at a heating rate of $10^{\circ} \mathrm{C} / \mathrm{min}^{-1}$ and nitrogen flow rate of $20 \mathrm{~mL} / \mathrm{min}^{-1}$. The test was performed according to ASTM standard E1868-10 (2015) and ASTM standard E1131-08 (2015).

\section{Differential spectroscopy calorimetry (DSC) of the biocomposites}

A DSC Mettler Toledo analytical instrument was used to conduct the thermal analysis. Differential scanning calorimetry was conducted to analyse the type of response given by the biocomposites via heating. The aim of conducting a DSC test is to investigate the melting point of the crystalline polymer or the glass transition point of a material. The test was performed according to ASTM standard D3418-15 (2015) and ASTM standard E1269-11 (2018), with a temperature of range of 40 to $400{ }^{\circ} \mathrm{C}$ at a heating rate of 10 ${ }^{\circ} \mathrm{C} / \mathrm{min}^{-1}$.

\section{RESULTS AND DISCUSSIONS}

\section{Scanning Electron Microscopy (SEM) of the Biocomposites}

Figures 1, 2, and 3 are the SEM images taken at 500x magnification to allow for a fair comparison between the control, PLA/BC, and PLA/PEMA/BC biocomposite samples. Figure 1 shows the SEM images for the PLA samples. PLA shows a smooth surface with shallow cracks, and PLA/PEMA has a slight contrast with crevices and a large chip-like appearance, which may denote slight ductile behavior, unlike PLA.
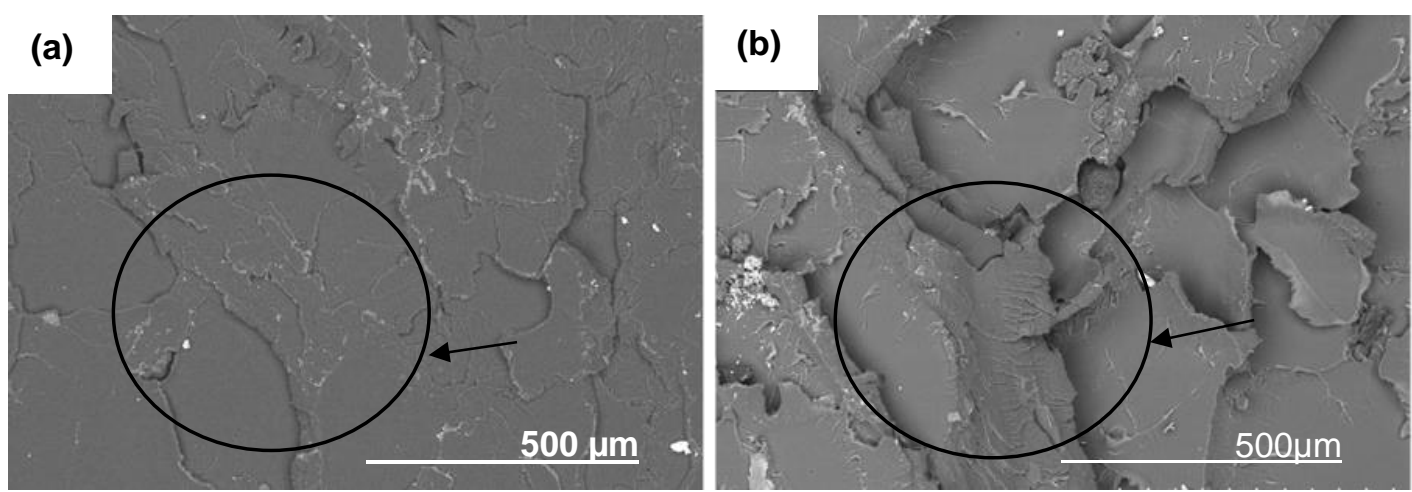

Fig. 1. SEM images of the fractured PLA samples at 500x magnification: (a) PLA and (b) PLA/PEMA 

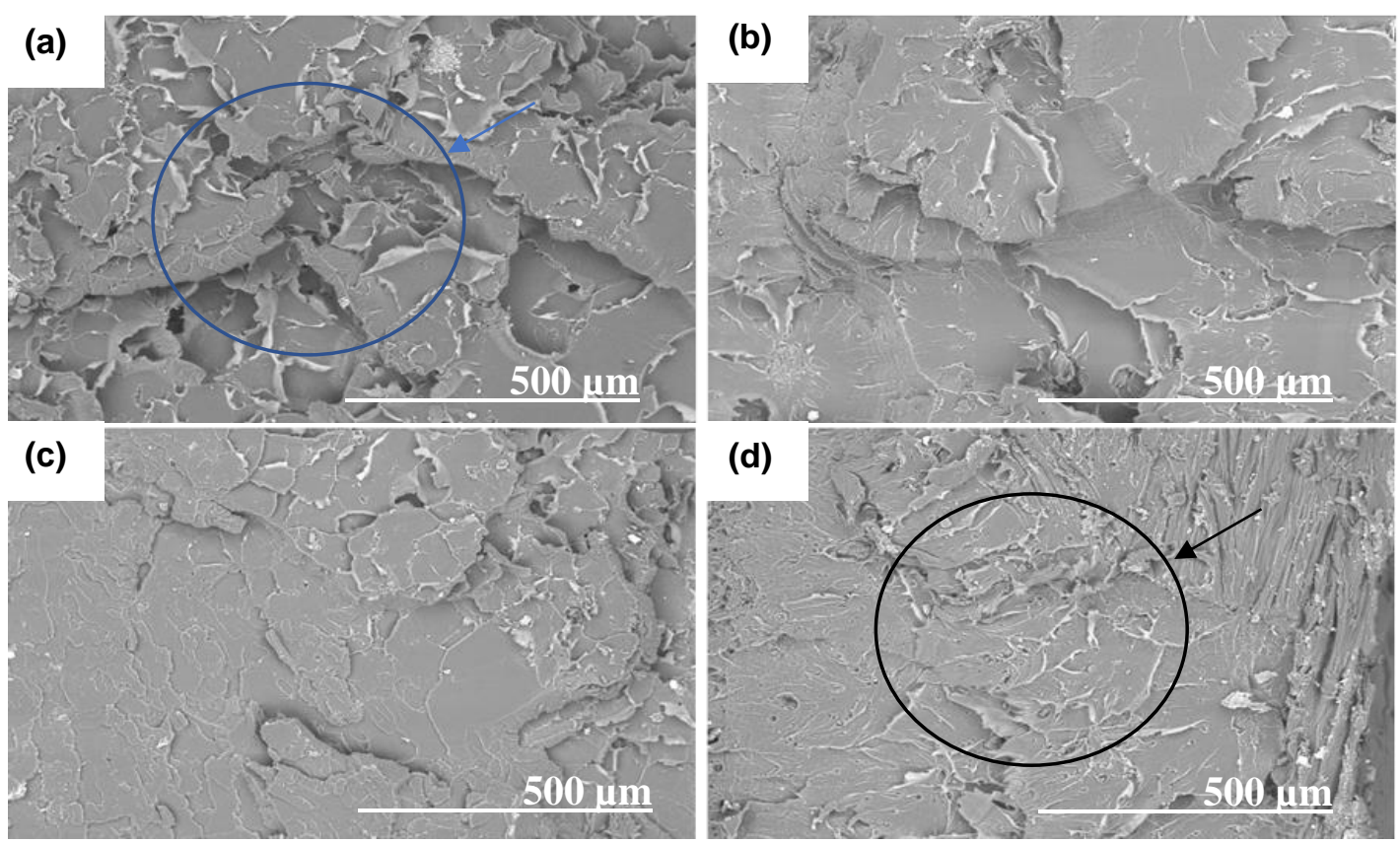

Fig. 2. SEM images of the fractured bio-composites at 500x magnification: (a) PLA/BC 0.5, (b) PLA/BC 1.25, (c) PLA/BC 1.625, and (d) PLA/BC 2.0
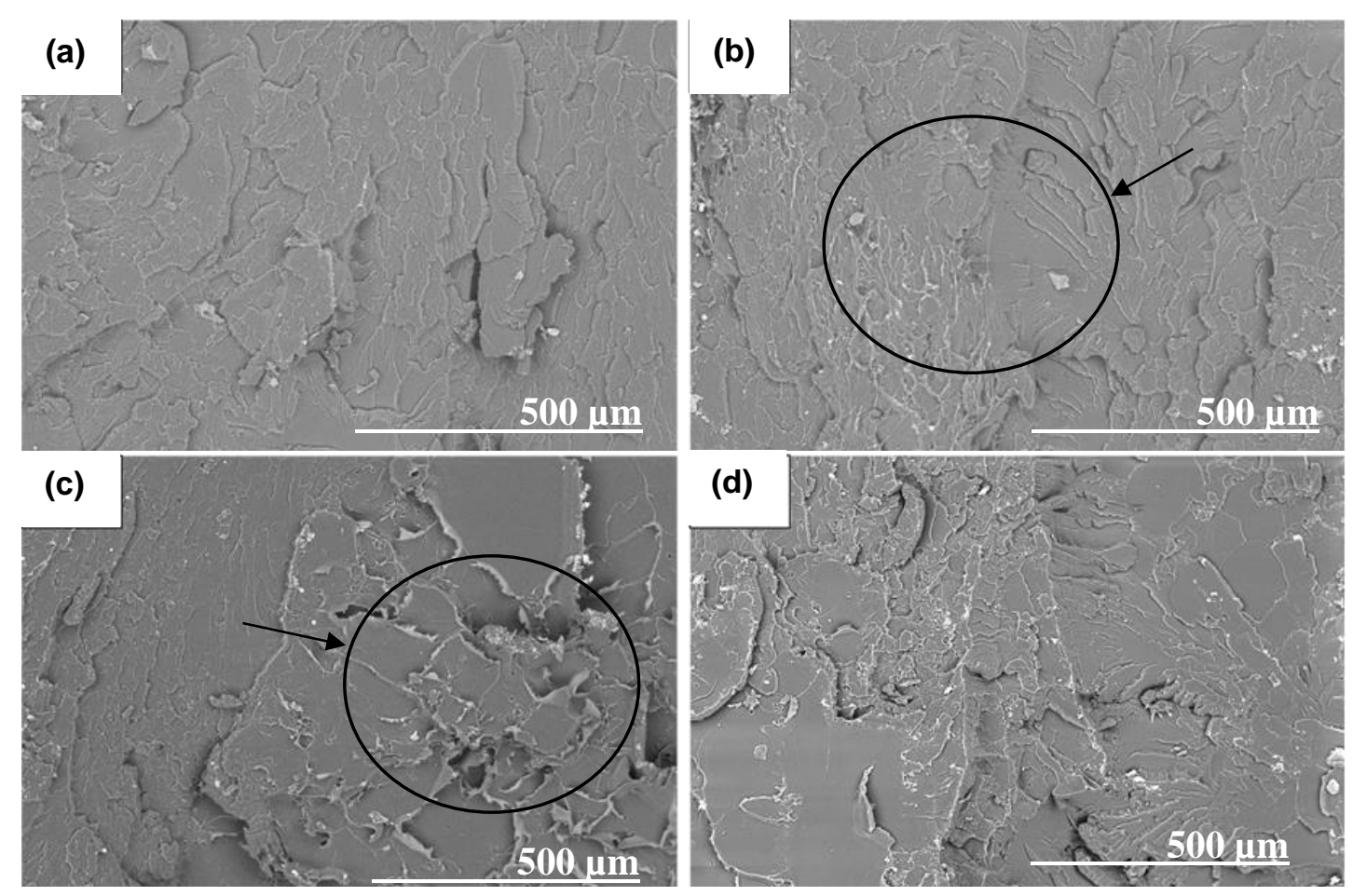

Fig. 3. The SEM images of the fractured bio-composites at 500x magnification: (a) PLA/PEMA/ BC 0.5, (b) PLA/PEMA/BC 1.25, (c) PLA/PEMA/BC 1.625, and (d) PLA/PEMA/BC 2.0

The addition of bio-filler in the PLA/PEMA/BC sample had a great effect on the surface structure in comparison to the surface structure of the fractured PLA samples. It seems that the addition of PEMA allowed the bio-filler to better distribute throughout the biocomposite and the bio-composite to obtain a slightly brittle nature. In contrast, the 
PLA/BC sample (Fig. 2) had a greater crevasse and void depth and demonstrated slight ductile behaviour due to chipping at the ends.

The voids and deep crevasses may be an indicator of trapped air caused via the agglomeration of bio-filler and compression during the manufacturing process. This is one of the manufacturing problems associated with the hot compression molding process. At higher bio-filler contents $(2.0 \mathrm{wt} \%)$, the surface structure was observed to be grainy, and the number of stress fractures increased in relation to a lower bio-filler content. The PLA/PEMA/BC sample (Fig. 3) showed that the addition of PEMA had an impact on the distribution of the bio-filler inside the matrix, which resulted in a smoother surface compared to the PLA/BC samples. However, voids (trapped air pockets) were still present, which produced flaws similar to those shown in Fig. 2 (PLA/BC). The fracture regions in the PLA/PEMA/BC sample did not exhibit as much chipping as the PLA/BC samples but had a smooth grainy surface structure. However, a majority of the samples exhibited brittle fracture characteristics; these findings were comparable to other studies based on characterizing reinforced polymer composites via mechanical testing (Chen et al. 2008; Korayem et al. 2014; Spinelli et al. 2019).

\section{Fourier Transform Infrared Spectroscopy (FTIR) of the Biocomposites}

The FTIR spectra of the PLA samples, and the PLA/BC and PLA/PEMA/BC biocomposites are shown in Figs. 4, 5, and 6, respectively. The regions of interest for the PLA samples and the bio-composites are between wavenumber 1780 and $1680 \mathrm{~cm}^{-1}$ for the $\mathrm{C}=\mathrm{O}$ stretch, and between 3600 and $3000 \mathrm{~cm}^{-1}$ for the $\mathrm{O}-\mathrm{H}$ stretch. However, there were no major peaks present in the biocomposites or the PLA samples within the 3600 to 3000 $\mathrm{cm}^{-1}$ region. This demonstrates that the moisture content and number of alcohol groups present in the samples were low (Deng et al. 2020). However, there were major peaks observed from the $\mathrm{C}-\mathrm{O}$ stretching at $1320 \mathrm{~cm}^{-1}$ to $1210 \mathrm{~cm}^{-1}$ and the $\mathrm{O}-\mathrm{H}$ bending at 1440 to $1395 \mathrm{~cm}^{-1}$ and 950 to $910 \mathrm{~cm}^{-1}$. The peaks at wavenumber region 1750 and $1180 \mathrm{~cm}^{-1}$ were characterized as $\mathrm{C}=\mathrm{O}$ stretching; the $\mathrm{C}-\mathrm{O}-\mathrm{C}$ stretching seen in PLA are visible in the spectra of PLA/PEMA, as well as in the biocomposites (Mofokeng et al. 2012).

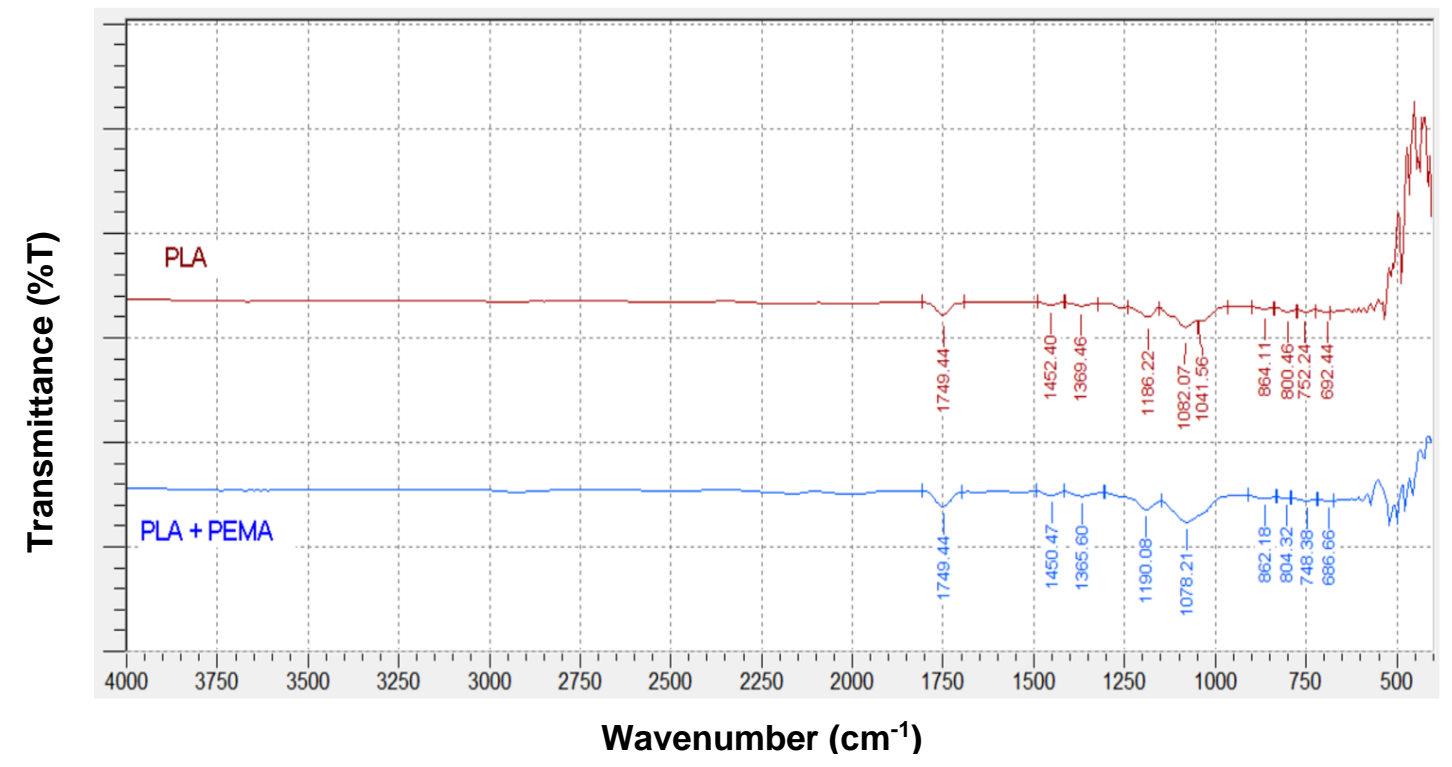

Fig. 4. The FTIR spectra graph for the PLA and PLA+PEMA samples 


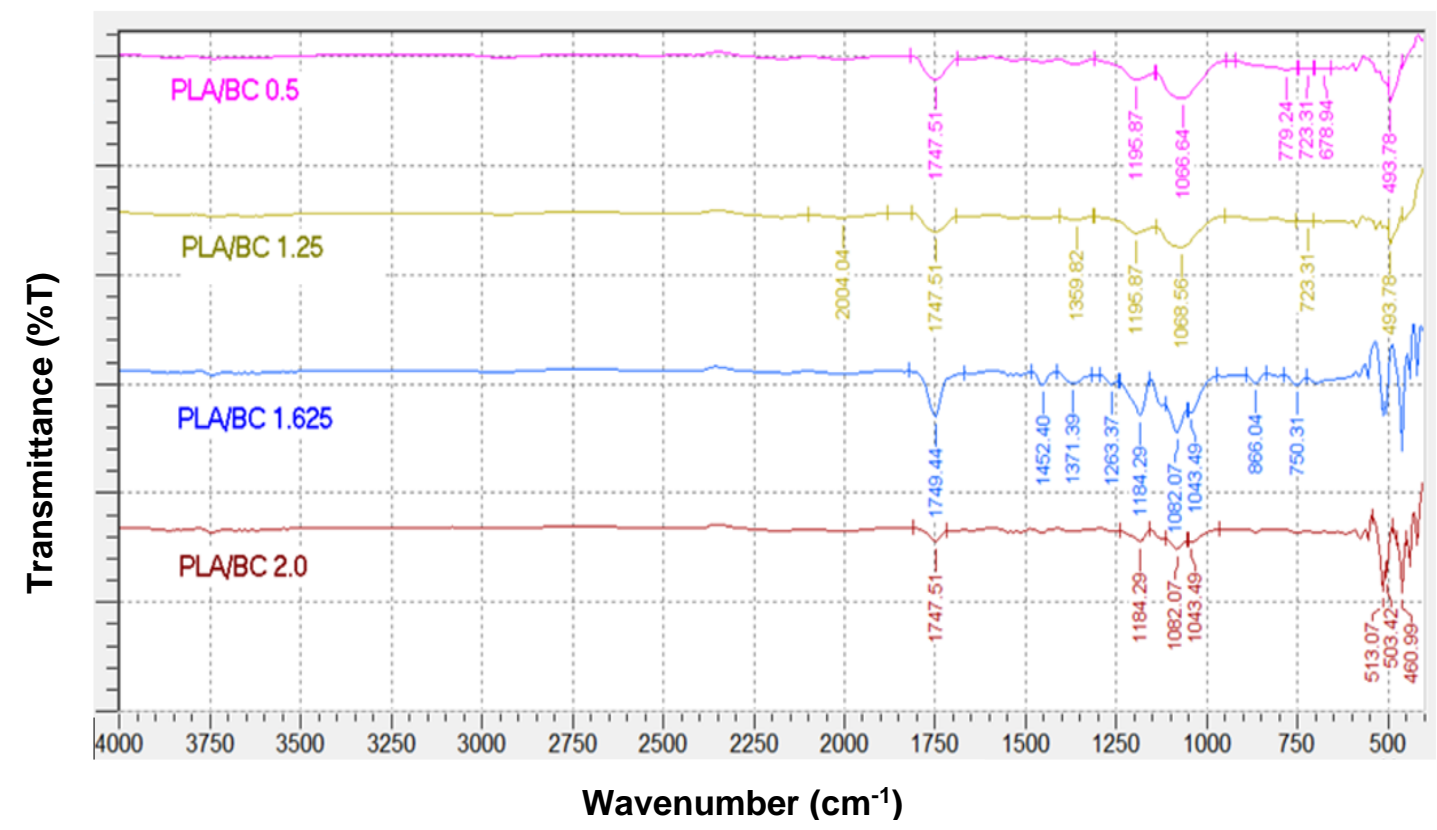

Fig. 5. The FTIR spectra graph for the PLA/BC with different compositon biocomposites

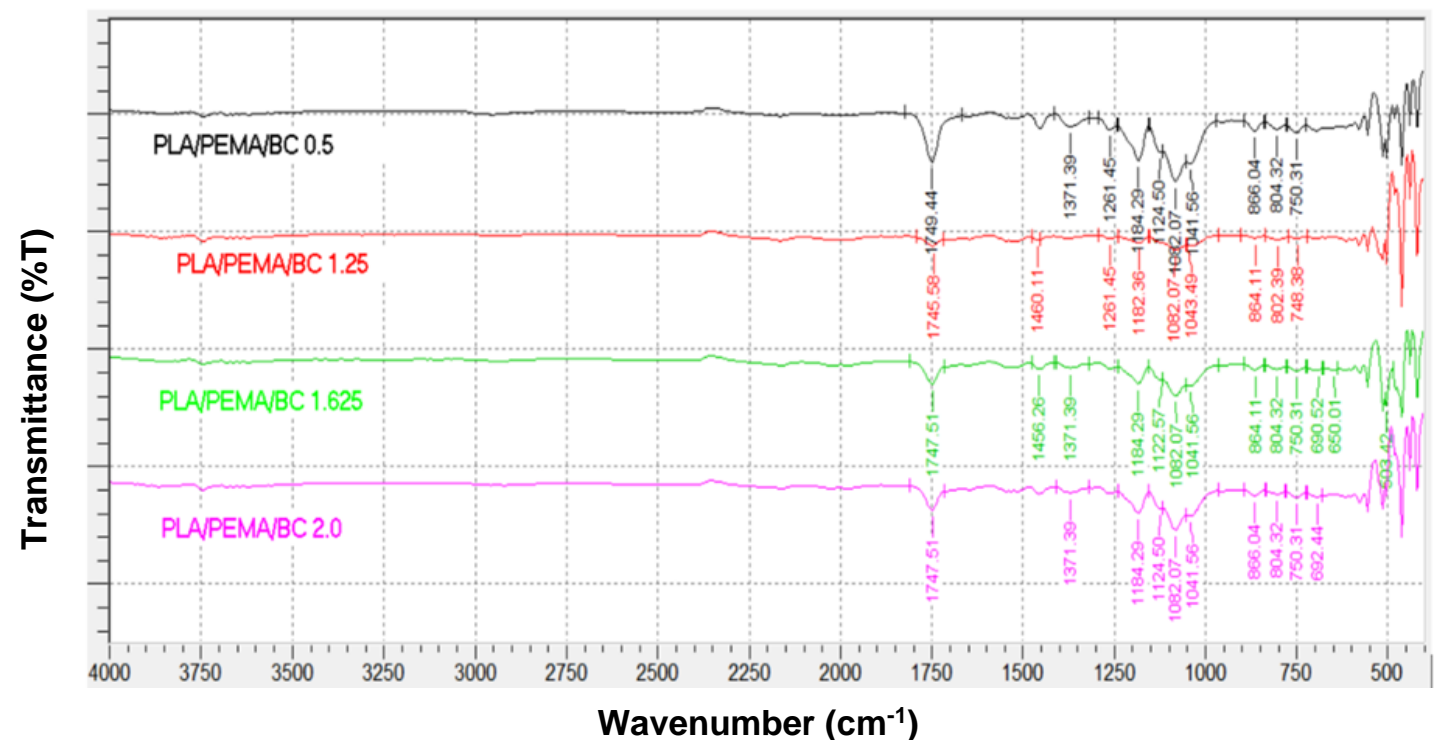

Fig. 6. The FTIR spectra graph for the PLA/PEMA/BC biocomposites

As shown in Fig. 4, the combined spectra exhibit comparable peaks starting at wavenumbers 1800 to $500 \mathrm{~cm}^{-1}$, which did not drastically alter the transmittance intensity of $100 \% \mathrm{~T}$ to $110 \% \mathrm{~T}$. However, the PLA/PEMA sample showed a slightly higher peak intensity between wavenumbers 1200 and $1000 \mathrm{~cm}^{-1}$, which is characterized as C-C and C$\mathrm{O}$ stretching. The peaks are affected by the incorporation of PEMA into the PLA matrix. These findings are similar to a study by Nizamuddin et al. (2019) on polylactide/rice husk hydro-char composites, where the FTIR peaks for the neat samples were most prominent between 1800 and $500 \mathrm{~cm}^{-1}$. 
Figure 5 shows the FTIR spectra for the PLA/BC biocomposites, where it is apparent that the overall peaks were also comparable to the PLA/BC samples. It was observed that the major peaks occurred between 1800 and $500 \mathrm{~cm}^{-1}$. However, it was observed that the PLA/BC biocomposite samples of a different mixture content (PLA/BC 1.625), had a higher peak intensity ranging from 1200 to $1000 \mathrm{~cm}^{-1}$, which is characteristic as $\mathrm{C}-\mathrm{H}$ bonds, and may affect the thermal properties shown in the TGA and DSC results (Deng et al. 2020).

Figure 6 shows the FTIR spectra for the PLA/PEMA/BC biocomposites, which were similar to the PLA/BC biocomposites. The PLA/PEMA/BC 0.5 sample had peaks that were more pronounced than the higher bio-filler content biocomposites, which affects the thermal properties shown in the TGA and DSC results. The addition of PEMA assisted the lower bio-filler content in achieving better bonding between the bio-filler and the matrix; the higher bio-filler content did not benefit from the addition of PEMA, as the peak intensities were reduced (Das et al. 2016; Poulose et al. 2018). The more pronounced peaks show that the interaction between the bio-filler and the matrix was better, which may correlate to the thermal property performance determined via TGA and DSC thermal analysis. This correlation between the peak intensity and the thermal properties are similar to those observed by Deng et al. (2020). In addition, the bio-filler did not greatly alter the functional groups in the biocomposite samples with increased bio-filler content (Poulose et al. 2018; Nizamuddin et al. 2019).

\section{Thermogravimetric Analysis (TGA) of the Biocomposites}

Thermogravimetric analysis was used to determine the thermal stability and the percentage weight loss of the biocomposites, either as a function of time or temperature under a constant rate of heating. The thermal degradation behaviors were plotted to determine the thermal stability of the biocomposites. The TGA performed on both the control PLA and PLA/PEMA samples were interpreted as a single step decomposition, according to the TGA plot shown in Fig. 7.

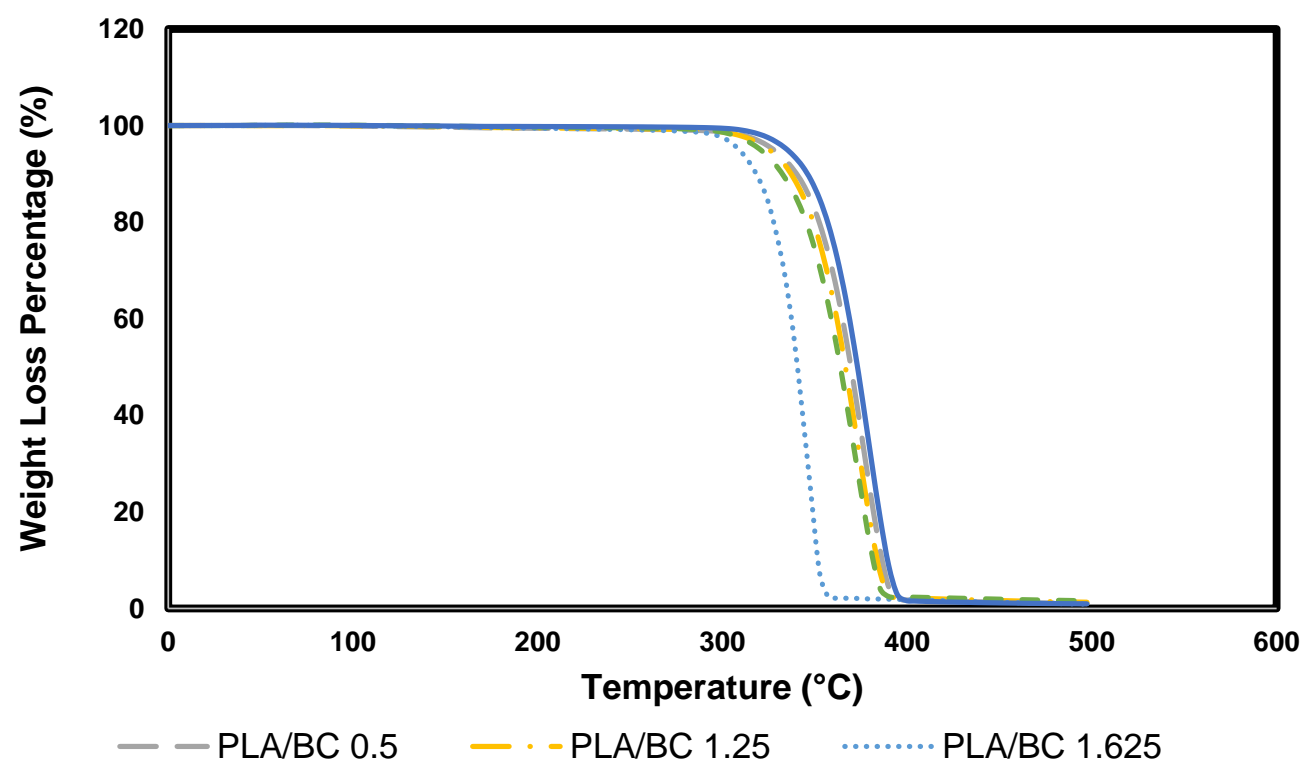

Fig. 7. The TGA graph for the PLA/BC at different percentages 
Thermal decomposition of PLA was observed at temperatures ranging from 281.7 to $427.0{ }^{\circ} \mathrm{C}$, with a residue amount of $1.32 \%$ and a weight loss of $98.3 \%$. Thermal decomposition of PLA/PEMA was observed at temperatures ranging from $292.9{ }^{\circ} \mathrm{C}$ to $412.2{ }^{\circ} \mathrm{C}$, with a residue amount of $1.61 \%$ and a weight loss of $97.3 \%$.

According to the TGA plot shown in Fig. 7, the PLA/BC biocomposites are interpreted as a single step decomposition and are similar to the thermal decomposition behavior of the PLA sample. In comparison to the PLA sample, the PLA/BC 1.625 sample showed the largest single step decomposition change, where the thermal decomposition of the PLA/BC 1.625 sample was observed between temperatures of 263.6 and $385.2{ }^{\circ} \mathrm{C}$ with a residue amount of $1.97 \%$ and a weight loss of $97.1 \%$. It is expected for a polymer composite with a carbon-based filler to have lower thermal stability due to nonhomogenous mixing and poor compatibility issues compared with other samples (Nizamuddin et al. 2019). A similar thermal decomposition behavior can be observed in Fig. 8 .

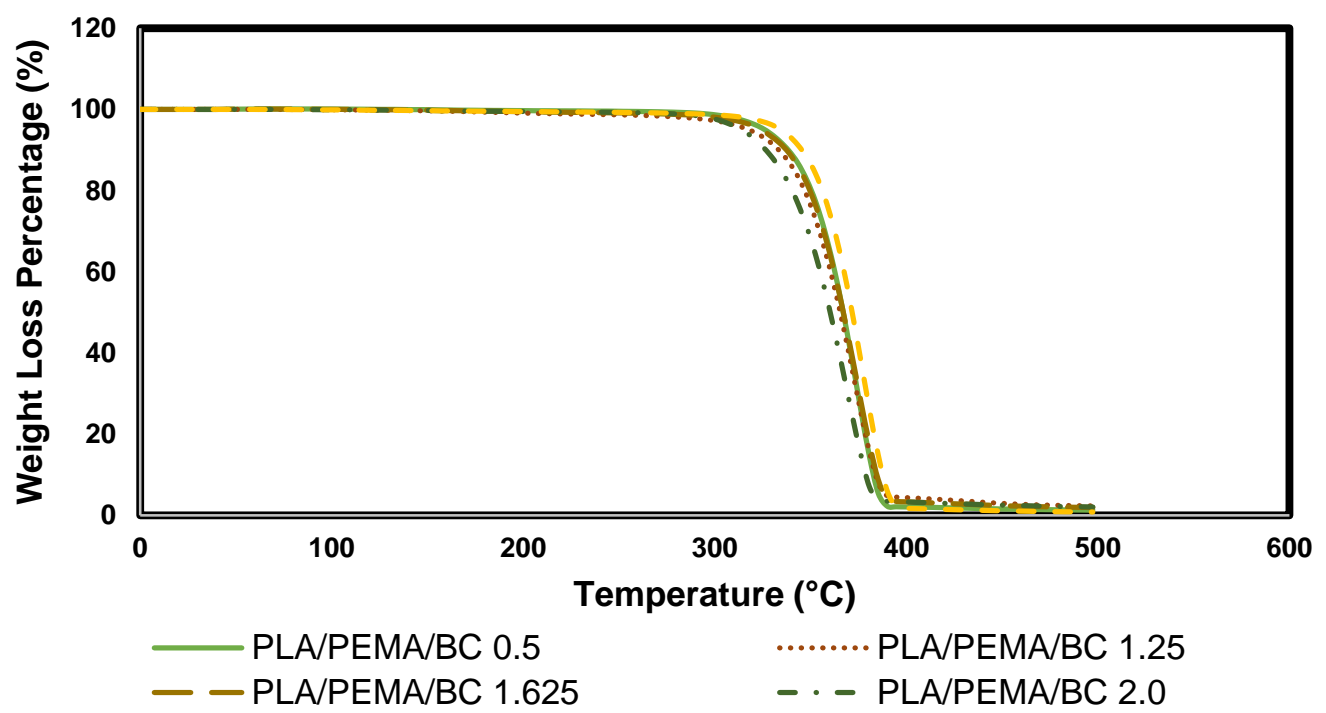

Fig. 8. The TGA graph for the PLA/PEMA and PLA/PEMA/BC biocomposites

According to Fig. 8, the PLA/PEMA/BC 2.0 biocomposite had the greatest change in terms of thermal decomposition at a slightly lower temperature, followed by the PLA/PEMA/BC biocomposites, and then the PLA/PEMA biocomposites. The thermal decomposition of PLA/PEMA/BC 2.0 was observed in a temperature range from $257.9^{\circ} \mathrm{C}$ to $398.2{ }^{\circ} \mathrm{C}$, with a residue amount of $3.38 \%$ and a weight loss of $95.8 \%$. In general, the thermal stability of the biocomposites could be attributed to the additional hydroxyl group, via the addition of PEMA into the biocomposite mixture, which affected the interaction between the filler and the polymer matrix (Mohanty and Nayak 2010). It should be noted that a majority of the weight loss was from the PEMA and PLA matrix, as these polymer materials have a lower melting temperature than the bio-filler (Nizamuddin et al. 2019). Overall, the addition of bio-filler into the matrix affected the biocomposite, causing it to undergo thermal decomposition at a slightly lower temperature. However, the bio-filler is in a charred state; as such, further thermal decomposition at higher temperatures may result in the bio-filler being converted into ash, i.e., residue. This would contribute to an increase 
in residue amount for higher bio-filler content biocomposites, as well as affecting the thermal properties of the biocomposite (Nizamuddin et al. 2019).

\section{Differential Scanning Calorimetry (DSC) of the Biocomposites}

The function of differential scanning calorimetry (DSC), as a method of thermal analysis, is to measure the heat flow enthalpy changes according to the changes in the chemical or physical properties of the sample as a function of time or temperature. The temperature melting point and the latent heat of melting $\Delta H_{\mathrm{m}}$ of the biocomposites and PLA samples are tabulated in Table 2. Figures 9 and 10, which show the DSC plots of the biocomposites and PLA samples, exhibit negative heat flow due to the endothermic reaction of the DSC test (Zhu et al. 2014).

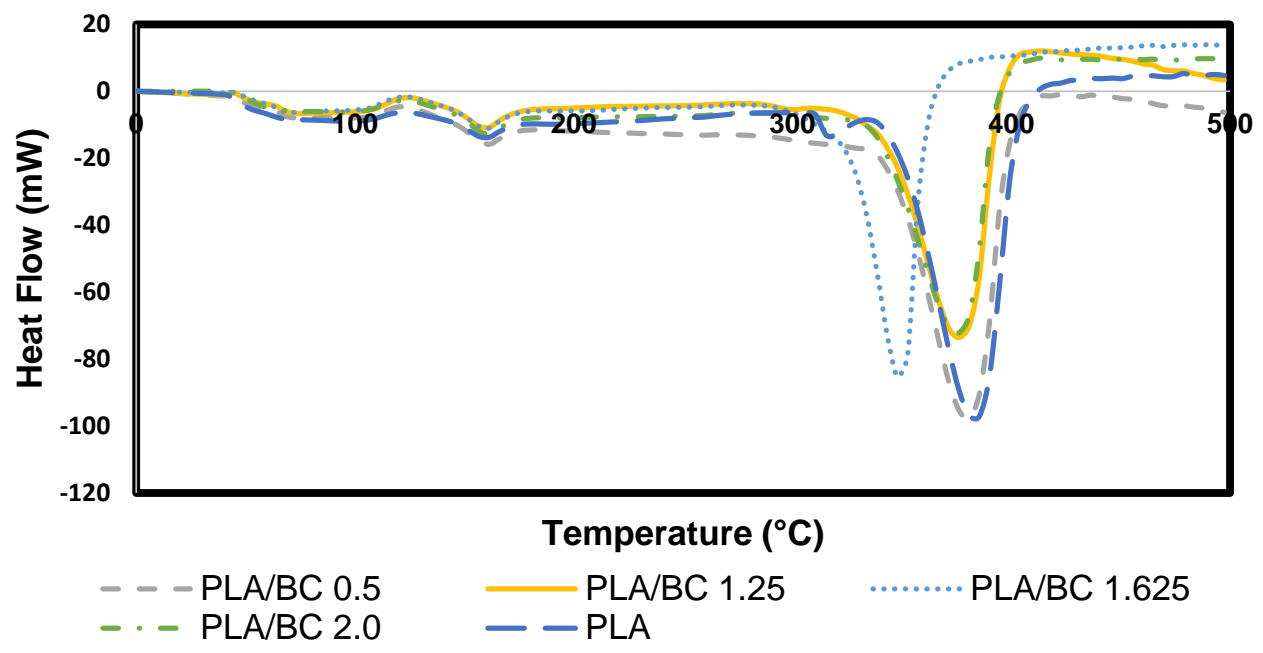

Fig. 9. The DSC graph for the PLA and PLA/BC biocomposites

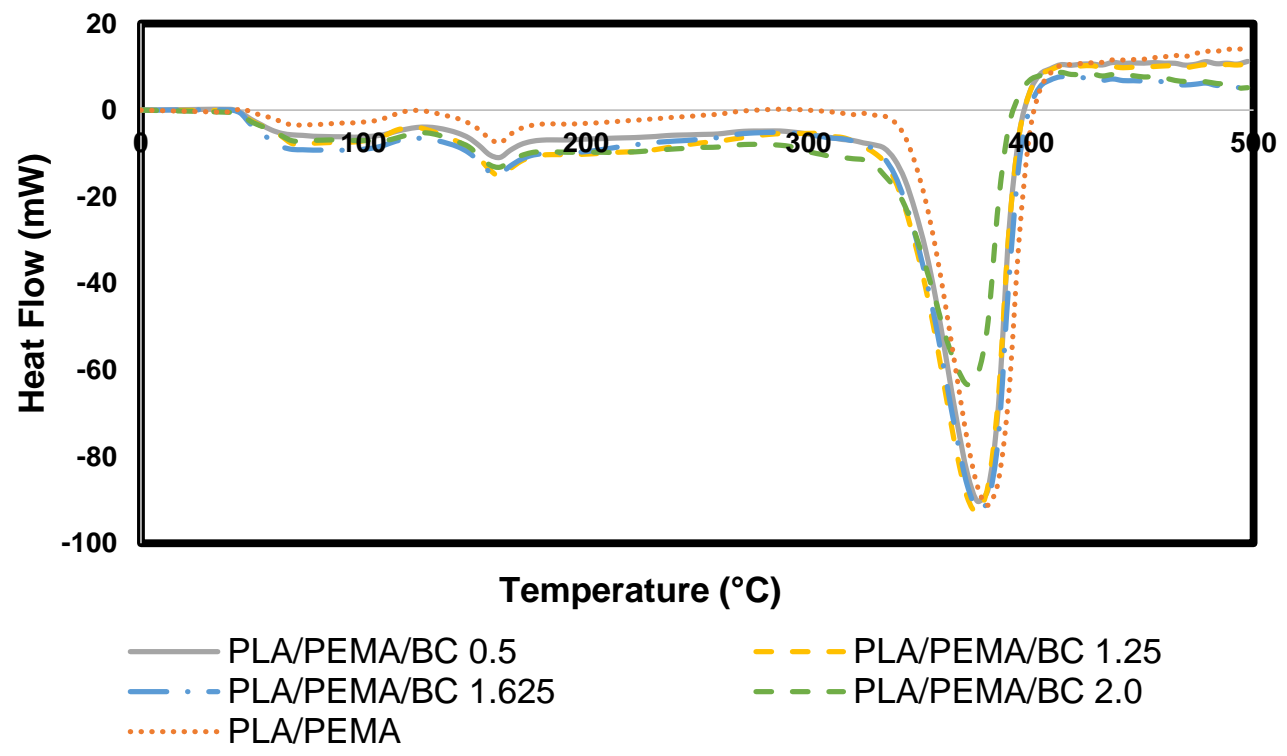

Fig. 10. The DSC for the PLA/PEMA and PLA/PEMA/BC biocomposites 
According to the DSC plots and the tabulated results for the PLA/BC biocomposite samples, it was observed that the overall initial melting temperature of the PLA/BC biocomposites samples slightly increased in value. By adding more bio-filler into the PLA matrix, the peak melting point, final melting temperatures, and the melting enthalpy were all slightly reduced in value.

Table 2. DSC Analysis of the Control and Biocomposite Samples

\begin{tabular}{|c|c|c|c|c|}
\hline Samples & $\begin{array}{c}\text { Initial Melting } \\
\text { Point }\left({ }^{\circ} \mathrm{C}\right)\end{array}$ & $\begin{array}{c}\text { Peak Melting } \\
\text { Temperature }\left({ }^{\circ} \mathrm{C}\right)\end{array}$ & $\begin{array}{c}\text { Final Melting } \\
\text { Point }\left({ }^{\circ} \mathrm{C}\right)\end{array}$ & $\begin{array}{c}\text { Melting Enthalpy } \\
\Delta \mathrm{H}_{\mathrm{m}}(\mathrm{mJ})\end{array}$ \\
\hline PLA & 293.01 & 381.13 & 404.02 & 10910.00 \\
\hline PLA/PEMA & 317.01 & 379.60 & 401.13 & 9958.29 \\
\hline PLA/BC 0.5 & 306.00 & 379.61 & 400.62 & 9898.47 \\
\hline PLA/BC 1.25 & 298.48 & 397.47 & 397.47 & 9022.00 \\
\hline PLA/BC 1.625 & 274.40 & 348.79 & 362.20 & 7366.89 \\
\hline PLA/BC 2.0 & 314.21 & 376.13 & 394.96 & 8008.75 \\
\hline $\begin{array}{c}\text { PLA/PEMA/BC } \\
0.5\end{array}$ & 317.58 & 377.80 & 396.20 & 9297.91 \\
\hline $\begin{array}{c}\text { PLA/PEMA/BC } \\
1.25\end{array}$ & 311.62 & 375.13 & 396.81 & 10460.00 \\
\hline $\begin{array}{c}\text { PLA/PEMA/BC } \\
1.625\end{array}$ & 318.86 & 377.83 & 397.30 & 10090.00 \\
\hline $\begin{array}{c}\text { PLA/PEMA/BC } \\
2.0\end{array}$ & 291.40 & 372.73 & 391.18 & 7653.01 \\
\hline
\end{tabular}

The thermal decomposition behavior observed in PLA/BC sample was similar to the DSC plot and tabulated results for the PLA/PEMA/BC sample. Due to the added compatibilizer (PEMA), the thermal decomposition of the biocomposites was affected; this caused the collective latent heat of enthalpy of the PLA/PEMA/BC biocomposites to slightly increase in comparison to the PLA/BC biocomposites. In contrast, the PLA/BC and PLA/PEMA/BC biocomposite are more thermally stable than their respective samples, i.e., PLA and PLA/PEMA. Nan et al. (2015) indicated that the variation in melting enthalpy with the addition of different amounts of bio-filler may be linked to the transformation of the crystalline properties of the composite samples. The added bio-filler did not have a major influence on the melting temperature of the composites. However, the latent enthalpy was drastically reduced. This behavior was attributed to the bio-filler particles acting as nucleation sites, which initiated crystal growth, therefore altering the temperature of crystallization. The increase in bio-filler content has an impact on the crystallization of biocomposites (Nizamuddin et al. 2019).

\section{CONCLUSIONS}

1. Based in Fourier transform infrared (FTIR) spectrometry, the addition of poly(ethylene-alt-maleic anhydride) (PEMA) assisted in lowering the bio-filler content needed to achieve better bonding between the bio-filler and the matrix, whereas at the higher bio-filler content it did not benefit from the addition of PEMA, as the peak intensities were reduced. The more pronounced peaks show the interaction between the bio-filler and the matrix was better, which may correlate to the thermal property 
performance determined via thermogravimetric analysis (TGA) and differential scanning calorimetry (DSC) thermal analysis. In addition, the bio-filler did not greatly alter the functional groups in the biocomposite samples with increased bio-filler content.

2. The TGA and DSC thermal analysis showed that the developed biocomposites had slightly greater thermal stability compared to the poly(lactic acid) (PLA) by itself and its composite with biochar (PLA/BC). The improvements in the thermal stability of the PLA/PEMA/BC sample could be attributed to the additional hydroxyl group caused by the added PEMA. According to the results of the analysis of the developed biocomposites, the biocomposites were more brittle and had reasonable thermal stability.

\section{ACKNOWLEDGMENTS}

The authors are grateful for the support of the Universiti Malaysia Sarawak (UNIMAS).

\section{REFERENCE CITED}

ASTM D3418-15 (2015). "Standard test method for transition temperatures and enthalpies of fusion and crystallization of polymers by differential scanning calorimetry," ASTM International, West Conshohocken, PA.

ASTM D638-14 (2014). "Standard test method for tensile properties of plastics," ASTM International, West Conshohocken, PA.

ASTM E1131-08 (2008). "Standard test method for compositional analysis by thermogravimetry," ASTM International, West Conshohocken, PA.

ASTM E1252-98 (2013). "Standard practice for general techniques for obtaining infrared spectra for qualitative analysis," ASTM International, West Conshohocken, PA.

ASTM E1269-11 (2018). "Standard test method for determining specific heat capacity by differential scanning calorimetry," ASTM International, West Conshohocken, PA.

ASTM E168-16 (2016). "Standard practices for general techniques of infrared quantitative analysis," ASTM International, West Conshohocken, PA.

ASTM E1868-10 (2015). "Standard test methods for loss-on-drying by thermogravimetry," ASTM International, West Conshohocken, PA.

ASTM E2015-04 (2014). "Standard guide for preparation of plastics and polymeric specimens for microstructural examination," ASTM International, West Conshohocken, PA.

Bogren, K. M., Gamstedt, E. K., Neagu, R. C., Aakerholm, M., and Lindström, M. (2006) "Dynamic-mechanical properties of wood-fiber reinforced polylactide: Experimental characterization and micromechanical modeling," Journal of Thermoplastic Composite Materials 19(6), 613-637. DOI: 10.1177/0892705706067480

Braun, B., Dorgan, J. R., and Knauss, D. M. (2006). "Reactively compatibilized cellulosic polylactide microcomposites," Journal of Polymers and the Environment 14(1), 49-58. DOI: 10.1007/s10924-005-8706-y 
Carels, N. (2009). "Chapter 2. Jatropha curcas: A review," Advances in Botanical Research 50, 39-86. DOI: 10.1016/S0065-2296(08)00802-1

Chen, X., Wang, J., Lin, M., Zhong, W., Feng, T., Chen, X., Chen, J., and Xue, F. (2008). "Mechanical and thermal properties of epoxy nanocomposites reinforced with aminofunctionalized multi-walled carbon nanotubes," Materials Science and Engineering: A 492(1-2), 236-242. DOI: 10.1016/j.msea.2008.04.044

Das, O., Sarmah, A. K., and Bhattacharyya, D. (2016). "Biocomposites from waste derived biochars: Mechanical, thermal, chemical, and morphological properties," Waste Management 49, 560-570. DOI: 10.1016/j.wasman.2015.12.007

Deng, J., Xu, L., Liu, J., Peng, J., Han, Z., Shen, Z., and Guo, S. (2020). "Efficient method of recycling carbon fiber from the waste of carbon fiber reinforced polymer composites," Polymer Degradation and Stabilility 182, Article ID 109419. DOI: 10.1016/j.polymdegradstab.2020.109419

Figueiredo, M. K.-K., Romeiro, G. A., Silva, R. V. S., Pinto, R. A., Damasceno, R. N., d'Avila, L. A., and Franco, A. P. (2011). "Pyrolysis oil from the fruit and cake of jatropha curcas produced using a low temperature conversion (LTC) process: Analysis of a pyrolysis oil-diesel blend," Energy and Power Engineering 3(3), 332338. DOI: 10.4236/epe.2011.33041

Graupner, N., Herrmann, A. S., and Mussig, J. (2009). "Natural and man-made cellulose fibre-reinforced poly(lactic acid) (PLA) composites: An overview about mechanical characteristics and application areas" Composites Part A: Applied Science and Manufacturing 40(6-7), 810-821. DOI: 10.1016/j.compositesa.2009.04.003

Kanaujia, P. K., Naik, D. V., Tripathi, D., Singh, R., Poddar, M. K., Konathala, L. N. S. K., and Sharma, Y. K. (2016). "Pyrolysis of Jatropha Curcas seed cake followed by optimization of liquid-liquid extraction procedure for the obtained bio-oil," Journal of Analytical and Applied Pyrolysis 118, 202-224. DOI: 10.1016/j.jaap.2016.02.005

Khui, P. L. N., Rahman, R., Hamdan, S., Jayamani, E., Bakri, M. K. B., and Sanaullah, K. (2020). "Synthesis and characterization of micro-nano carbon filler from jatropha seeds," BioResources 15(2), 3237-3251. DOI: 10.15376/biores.15.2.3237-3251

Korayem, A. H., Barati, M. R., Simon, G. P., Zhao, X. L., and Duan, W. H. (2014). "Reinforcing brittle and ductile epoxy matrices using carbon nanotubes masterbatch," Composites Part A: Applied Science and Manufacturing 61, 126-133. DOI: 10.1016/j.compositesa.2014.02.016

Lee, S.-H., and Wang, S. (2006). "Biodegradable polymers/bamboo fiber biocomposite with bio-based coupling agent," Composites Part A: Applied Science and Manufacturing 37(1), 80-91. DOI: 10.1016/j.compositesa.2005.04.015

Lezak, E., Kulinski, Z., Masirek, R., Piorkowska, E., Pracella, M., and Gadzinowska, K. (2008). "Mechanical and thermal properties of green polylactide composites with natural fillers," Macromolecular Biosience 8(12), 1190-1200. DOI: 10.1002/mabi.200800040

Masirek, R., Kulinski, Z., Chionna, D., Piorkowska, E., and Pracella, M. (2007). "Composites of poly(L-lactide) with hemp fibers: Morphology and thermal and mechanical properties" Journal of Applied Polymer Science 105(1), 255-268. DOI: 10.1002/app.26090

Mathew, A. P., Oksman, K., and Sain, M. (2005). "Mechanical properties of biodegradable composites from poly lactic acid (PLA) and microcrystalline cellulose (MCC)," Journal of Applied Polymer Sciece 97(5), 2014-2025. DOI: 10.1002/app.21779 
Mohamed, A. A., Finkenstadt, V. L., and Palmquist, D. E. (2007). "Thermal properties of extruded/injection-molded poly(lactic acid) and biobased composites," Journal of Applied Polymer Science 107(2), 898-908. DOI: 10.1002/app.26496

Mofokeng, J. P., Luyt, A. S., Tábi, T., and Kovacs, J. (2012). “Comparison of injection moulded, natural fibre reinforced composites with PP and PLA as matrices," Journal of Thermoplastic Composite Materials 25(8), 927-948. DOI: $10.1177 / 0892705711423291$

Mohanty, S. and Nayak, S. K. (2010). "Short bamboo fiber-reinforced HDPE composites: Influence of fiber content and modification on strength of the composite," Journal of Reinforced Plastics and Composites 29(14), 2199-2210. DOI:

10.1177/0731684409345618

Nizamuddin, S., Jadhav, A., Qureshi, S. S., Baloch, H. A., Siddique, M. T. H., Mubarak, N. M., Griffin, G., Madapusi, S., Tanksale, A., and Ahamed, M. I. (2019). "Synthesis and characterization of polylactide/rice husk hydrochar composite," Scientific Reports 9, 1-11. DOI: 10.1038/s41598-019-41960-1

Nyambo, C., Mohanty, A. K., and Misra, M. (2010). "Polylactide-based renewable green composites from agricultural residues and their hybrids," BioMacromecules 11(6), 1654-1660. DOI: $10.1021 / \mathrm{bm} 1003114$

Oksman, K., Skrifvars, M., and Selin, J.-F. (2003). "Natural fibres as reinforcement in polylactic acid (PLA) composites," Composites Science and Technology 63(9), 13171324. DOI: 10.1016/S0266-3538(03)00103-9

Pan, P., Zhu, B., Kai, W., Serizawa, S., Iji, M., and Inoue, Y. (2007). “Crystallization behavior and mechanical properties of bio-based green composites based on poly(Llactide) and kenaf fiber," Journal of Applied Polymer Science 105(3), 1511-1520. DOI: 10.1002/app.26407

Petersson, L., Kvien, I., and Oksman, K. (2007). "Structure and thermal properties of poly(lactic acid)/cellulose whiskers nanocomposite materials," Composites Science and Technology 67(11-12), 2545-2544. DOI: 10.1016/j.compscitech.2006.12.012

Poulose, A. M., Elnour, A. Y., Anis, A., Shaikh, H., Al-Zahrani, S. M., George, J., AlWabel, M. I., Usman, A. R., Ok, Y. S., Tsang, D. C. W., et al. (2018). "Date palm biochar-polymer composites: An investigation of electrical, mechanical, thermal and rheological characteristics," Science of The Total Environment 619-620, 311-318. DOI: 10.1016/j.scitotenv.2017.11.076

Ruggiero, A., Valášek, P., Müller, M., and D’Amato, R. (2019). “Tribological investigation of epoxy/seed particle composite obtained from residues of processing Jatropha Curcas L. fruits," Composites Part B: Engineering 167, 654-667. DOI: 10.1016/j.compositesb.2019.03.041

Spinelli, G., Lamberti, P., Tucci, V., Kotsilkova, R., Ivanov, E., Menseidov, D., Naddeo, C., Romano, V., Guadagno, L., Adami, R., et al. (2019). "Nanocarbon/poly(lactic) acid for 3D printing: Effect of fillers content on electromagnetic and thermal properties," Materials 12(15), 2369-2389. DOI: 10.3390/ma12152369

Sugumaran, V., Prakash, S., Ramu, E., Arora, A. K., Bansal, V., Kagdiyal, V., and Saxena, D. (2017). "Detailed characterization of bio-oil from pyrolysis of non-edible seed-cakes by Fourier Transform Infrared Spectroscopy (FTIR) and gas chromatography mass spectrometry (GC-MS) techniques," Journal of Chromatography B 1058, 47-56. DOI: 10.1016/j.jchromb.2017.05.014

Zhu, F.-R., Zhang, L., Zeng, J.-L., Zhu, L., Zhu, Z., Zhu, X.-Y., Li, R.-H., Xiao, Z.-L., and Cao, Z. (2014). "Preparation and thermal properties of palmitic acid/polyaniline/ 
copper nanowires form-stable phase change materials," Journal of Thermal Analysis and Calorimetry 115(2), 1133-1141. DOI: 10.1007/s10973-013-3508-2

Zini, E., Baiardo, M., Armelao, L., and Scandola, M. (2004). "Biodegradable polyesters reinforced with surface-modified vegetable fibers," Macromolecular Bioscience 4(3), 286-295. DOI: 10.1002/mabi.200300120

Article submitted: December 16, 2020; Peer review completed: February 27, 2021;

Revised version received and accepted: March 7, 2021; Published: March 11, 2021.

DOI: 10.15376/biores.16.2.3171-3185 